\title{
Short comment about the octopus life cycle in the northern Alboran Sea (western Mediterranean Sea).
}

\author{
Maria del Carmen Garcia Martinez ${ }^{1,2 *}$, Francina Moya ${ }^{1}$, Maria Gonzalez ${ }^{1,2}$, Pedro Torres ${ }^{1}$, Sara \\ Farzaneh $^{3}$, Manuel Vargas-Yanez ${ }^{1}$
}

${ }^{1}$ Centro Oceanográfico de Málaga. Puerto pesquero de Fuengirola, Spain

${ }^{2}$ Universidad de Málaga, Spain

${ }^{3}$ Universidad de Vigo, Spain

\begin{abstract}
Octopus vulgaris is a plastic species capable of adapting to different environmental conditions. The different phases of its life cycle seem to be highly influenced by such environmental variables. Therefore the reproductive season and the length of its embryonic and planktonic phases can differ substantially for different geographical areas. The Mediterranean Sea is one of the regions were the octopus life cycle is not yet well known. Biological data in the Alboran Sea (Western Mediterranean) in the present work show the existence of migration movements to coastal waters for the breeding season during spring and mainly during summer. Water temperature measurements show that the length of the embryonic and paralarval phases are around 120 days and new individuals incorporate to fisheries from autumn to winter. These results coincide with landings time series allowing the full description of the $O$. vulgaris life cycle.
\end{abstract}

Keywords: Reproductive stages, Spawning and settling, Cephalopods, Environmental factors.

Accepted on December 26, 2017

\section{Introduction}

Octopus vulgaris is a short lived species (1-2 years) with environmental adaptive plasticity [1,2]. Environmental factors seem to modulate its reproductive season. Rocha et al. [3] found that the hatching period in Galician waters was mainly at the end of spring and during summer when the upwelling season favors pray availability. Lourenço et al. [1] found that the spawning season in the Portuguese coast had two peaks in February-April and in June-July in the northwest, coinciding with the upwelling period. The spawning season was mainly during summer in the southern coast due to more stable conditions [3]. Both the duration of the embryonic and the paralarval or planktonic phases seem to be determined by the temperature of sea water [4]. Therefore the spawning period, the existence of one or two spawning peaks and the length of the embryonic and planktonic phases of the octopus life cycle seem to be highly dependent on environmental variables such as temperature, upwelling and wind intensity or zooplankton abundance $[1,5]$ and the time and length of the different phases of the octopus life cycle can differ from different geographical areas [1,6]. According to González et al. [7] the reproductive cycle of $O$. vulgaris is not yet well known in the Mediterranean Sea. Most of previous works focus on a specific phase of octopus life cycle, breeding season, length of the embryonic and paralarval phases or adults abundances. The main objective of the present work is to describe the complete life cycle of $O$. vulgaris considering information from the different phases of such cycle. It is established the time for the reproductive season and the existence of possible migratory movements associated to it, the length of the embryonic and paralarval phases, and the time of the settlement and, finally, the recruitment period which should be coincident with maximum landings of this species.

\section{Data and Methods}

Monthly Octopus vulgaris landings in the northern Alboran Sea ports in Figure 1 were obtained from the FROM (Organization and Regulation Fund for Fisheries and Aquaculture products) and the Junta de Andalucía Agriculture and Fisheries council. The complete data set extended from 1987 to 2008 [8] for a complete description. In addition, the Spanish Institute for Oceanography (IEO) collected octopus landings for biological analyses in Fuengirola and Malaga ports from 1999 to 2008 (Figure 1). This sampling was carried out in the frame of the Spanish National Data Collection program. These landings corresponded to both the artisanal fleet (clay pots) and the trawling fleet. The biological analysis included measurements of the dorsal mantle length in mm (DML), total weight in $\mathrm{g}$ (TW), sex determination and gonad weight (GW). Following Quetglas et al. [9] and Sánchez and Obarti [10] the maturity state was determined establishing three possible states: I) immature (ovary whitish, very small and with no signs of granulation in females; spermatophoric organ transparent in males), II) maturing (ovary yellowish with a granular structure; spermatophoric organ with white streaks), III) mature (ovary very large with plenty of eggs; spermatophoric sac with spermatophores) [11].

$$
G S I=\frac{G W}{T W-G W} \cdot 100
$$

Daily sea temperature data in the Fuengirola beach were used to estimate the average or climatological annual cycle of the coastal waters temperature in the northern Alboran Sea. These measurements were obtained in the frame of the monitoring program RADMED, carried out by the Spanish Institute for Oceanography in the Spanish Mediterranean waters [12]. According to Katsanevakis and Verriopoulos [4] the length of the octopus embryonic phase is given by the solution of the equation: 
Citation: Martinez MDCG, Moya F, Gonzalez M, et al. Short comment about the octopus life cycle in the northern Alboran Sea (western Mediterranean Sea). J Fish Res. 2017;1(1):11-37.

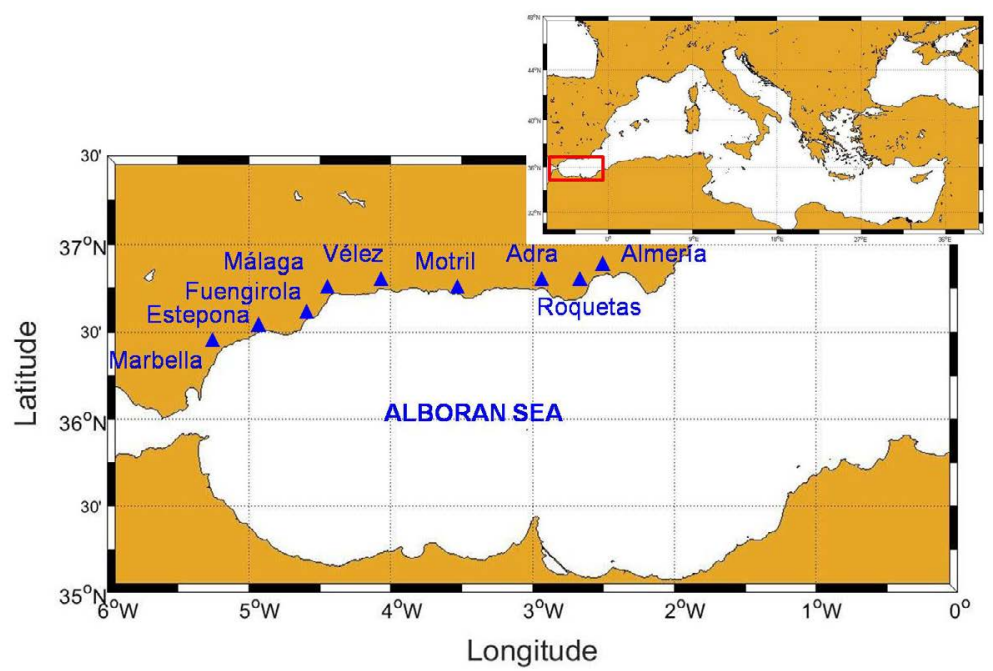

Figure 1. Alboran Sea and location of the ports in its northern coast where octopus landings were obtained.

$$
\int_{t s}^{t h} \frac{1}{I(T)} d t=1 \text { being } I(T)=\frac{532.2}{T-8.763}
$$

The instantaneous rate of development at temperature $T$. $t s$ is the spawning time and th the hatching time. The length of the paralarval phase, that is, from the hatching to the settlement of the individuals is given by the solution of equation:

$$
\int_{\text {th }}^{\text {tset }} \frac{1}{P(T)} d t \text { being } P(T)=157.5-5.008 T
$$

The instantaneous rate of development at temperature $T$. th is the hatching time and tset the settlement time. Both equations were solved using the annual evolution of the temperature in Fuengirola beach and the continental shelf temperature. Using the average or climatological annual or seasonal temperature cycle yields the average length for the embryonic and paralarval phases.

\section{Results}

The study area was divided into its western part (Estepona, Marbella, Fuengirola) and the eastern part (Vélez to Almería) (Figure 1). Figure 2A shows the average annual cycle for Landings in Estepona, Marbella and Fuengirola (blue continuous line) and in Velez, Motril, Adra, Roquetas and Almería (continuous red line). Malaga data were discarded after finding some errors in such time series. Dashed lines are 95\% confidence intervals for the seasonal mean values. These cycles are estimated using the complete time series from 1987 to 2008. Landings start increasing in autumn reaching maximum values from October to January and then decreasing during spring and summer. A secondary maximum is observed in June. Figure 2B shows the annual cycles for landings estimated using the time series from 1987 to 1999 . The reason for selecting this period of time is that fisheries regulations started in 2000 with the banning of fisheries for the month of May. Therefore the annual cycles estimated in Figure 2B are not influenced by such regulations. Notice that the general trend is similar to the one obtained in Figure 2A with winter maxima and decreasing values for spring and summer. The main difference is that the June secondary maximum is absent or negligible.
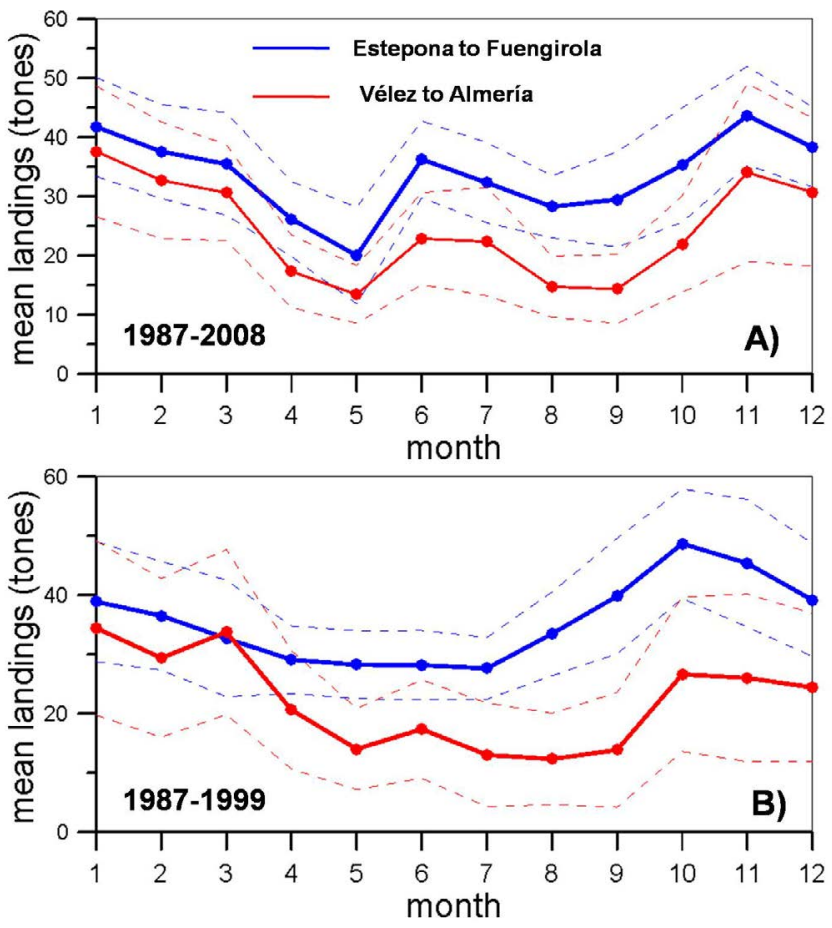

Figure 2. A) Landings in tons from 1987 to 2008 for the western ports (Estepona, Marbella and Fuengirola, blue lines) and eastern ports (Vélez to Almería, red lines). Málaga Port was not finally used because of some problems detected in such data. B) is the same but for the period 1987-1999. Dashed lines are the 95\% confidence intervals for the mean values.

Figure 3 shows the length of the $O$. vulgaris embryonic and paralarval phases as a function of the spawning day. The sum of both periods (red line) is the duration of the period of time between the spawning of the eggs and the settlement of the individuals. Curves in Figure 3 have been calculated using the annual temperature cycle for the Fuengirola beach. Notice that depending on the spawning day, the development of the eggs and then of the paralarvae occurs under different temperature conditions and therefore the length of such periods is different.

The spawning season was determined from maturity data. The proportion of mature males from the artisanal fleet was above 
$80 \%$ for all the months of the year whereas mature males from the trawling fleet decreased during spring and summer, increasing again in autumn and winter (not shown). Females show a very clear seasonal pattern. The proportion of mature females from the artisanal fleet increases from winter to spring reaching maximum values in summer and then decreasing

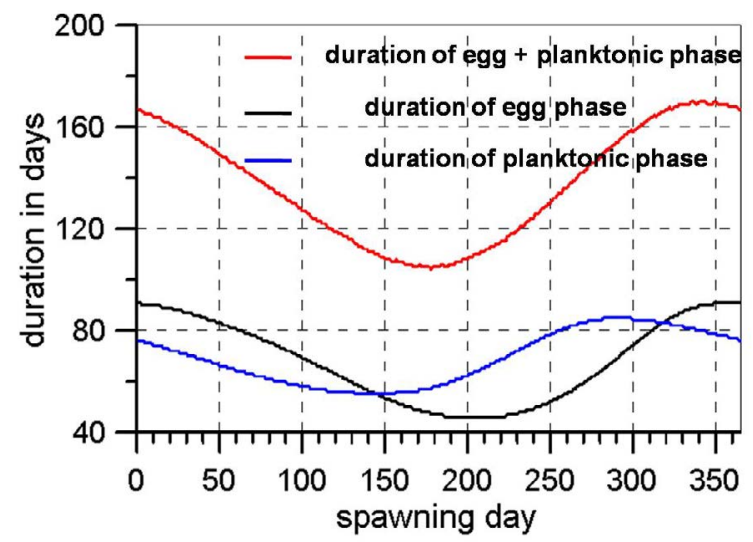

Figure 3. Black and blue lines are the duration in days of the embryonic and paralarval phases as a function of the spawning day. Red line is the sum of previous curves and represents the time in days between spawning and settlement, also expressed as a function of the spawning day.
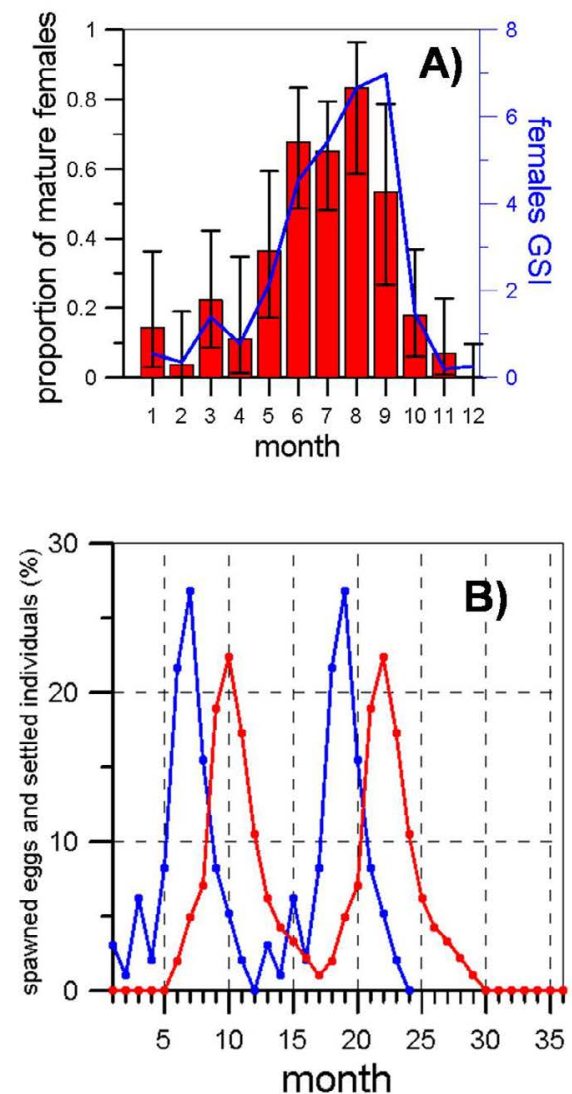

Figure 4. A) Bar plots are the proportions of mature females for each month of the year from the artisanal fleet. Error bars at the $95 \%$ confidence interval are included. Blue line is the females GSI. B) Blue line is the percentage of eggs spawned each month of the year. This percentage is calculated respect to the total amount of eggs spawned during the whole year. Red line is the percentage of individuals settled for each month of the year. again in autumn (Figure 4A, bar plot). The same behavior was observed for the GSI of females from the artisanal fleet (Figure 4A, blue line). The proportion of mature females from the trawling fleet was very low for all the months of the year with the only exception of June. Using maturity data, it was calculated the proportion represented by the number of mature females for each month with respect to the total number of mature females along one year. This proportion is considered to be the same as the proportion of eggs spawned for each month of the year (blue line in Figure 4B). Using the duration of embryonic plus paralarval phases estimated in Figure 2 it can be established the day of the year when the individuals spawned any day of the year will settle (red line, Figure 4B). Month 1 in Figure $4 \mathrm{~B}$ is January and the largest proportion of individuals settle in September, October and November, with the highest peak in October.

\section{Discussion and Conclusion}

Time series of octopus landings in the northern Alboarn Sea from 1987 to 2008 have been analyzed. Correlation between landings and landings per unit effort (when such data were available) shows that landing time series can be used as an indication of the octopus abundance [13]. According to these time series the average annual cycle of this species in the Alboran Sea shows an increase from the end of summer (July, August, September) reaching maximum abundances during the end of autumn (October, November, December) and winter (January, February, March). A secondary peak appears in June, but this peak disappears or is negligible if landings from 1987 to 1999 are used. This period of time is previous to the fisheries regulations. Therefore the high June abundances could only be the result of the fishery banning for the month of May. Landings in June would reflect the recruitment of new adults corresponding to June and also those corresponding to May when the octopus fishery is closed. Mature females decrease in spring and summer from the trawling landings which operate on the outer continental shelf. At the same time the number of mature females increases during spring and summer at coastal waters where the artisanal fleet operates (Figure 4A). Therefore the maturity data for octopus females suggest that there is a migration for breeding from the beginning of spring and during summer from the outer continental shelf to the coastal areas. Spawning occurs from spring to summer. The temperature in the coastal areas of the northern Alboran Sea determines the length of the embryonic and paralarval phases. Eggs spawned in spring and summer will last around 120 days until settlement. In order to estimate the number of individuals that settle each month it is necessary to consider the proportion of eggs spawned each month and the duration of the embryonic and planktonic phases of such individuals. In the case of the Alboran Sea, most of the individuals settle during autumn. Considering a few weeks or a month from the settlement until the incorporation to the fisheries, most of the individuals would be recruited during autumn and winter, coinciding with the observed maximum octopus landings. In this way the complete life cycle of the northern Alboran $O$. vulgaris is closed: There seems to be a migratory movement for breeding during spring and mainly in summer. Eggs spawned from May would hatch in July and settle in September, whereas those spawned in August (maximum spawning period) would 
hatch in October and settle in December. Finally the maximum abundance of adult individuals would be coincident with the maximum landings from October to January.

\section{Acknowledgments}

This work was carried out with the financial assistance of the Commission of the European Communities under the DG Fish Data Collection Regulation. Environmental data have been collected under RADMED project (series temporales de datos oceanográficos), funded by the Instituto Español de Oceanografía

\section{References}

1. Lourenço S, Moreno A, Narciso L, et al. Seasonal trends of the reproductive cycle of Octopus vulgaris in two environmentally distinct areas. Fish Res. 2012;127-8:116-24.

2. Puerta P, Hidalgo M, González M, et al. Role of hydroclimatic and demographic processes on the spatio-temporal distribution of cephalopods in the western Mediterranean. Marine Ecological Progress Series. 2014;514:105-18.

3. Rocha F, Guerra A, Prego R, et al. Cephalopod para larvae and upwelling conditions off Galician waters (NW Spain). J Plankton Res. 1999;21(1):21-33.

4. Katsanevakis S, Verriopoulos G. Modelling the effect of temperature on hatching and settlement patterns of meroplanktonic organisms: The case of the octopus. Scientia Marina. 2006;70(4):699-708.

5. Otero J, Álvarez-Salgado XA, González AF, et al. Bottomup control of common octopus Octopus vulgaris in the Galician upwelling system, northeast Atlantic Ocean. Marine Ecological Progress Series. 2008;362:181-92.
6. Sobrino I, Juárez A, Rey J, et al. Description of the clay pot fishery in the Gulf of Cádiz (SW Spain) for Octopus vulgaris: Selectivity and exploitation pattern. Fish Res. 2011;108:283-90.

7. González M, Barcala E, Pérez-Gil JL, et al. Fisheries and biology of Octopus vulgaris (Mollusca: Cephalopoda) in the Gulf of Alicante (northwestern Mediterranean). Mediterranean Marine Science. 2011;12(2):369-89.

8. García-Martínez MC, Moya F, González M, et al. Comparative pattern of Octopus vulgaris life cycle with environmental parameters in the Northern Alboran Sea (western Mediterranean). Turk J Fish Aqua Sci. 2018;18:247-57.

9. Quetglas A, Alemany F, Carbonell A, et al. Biology and fishery of Octopus vulgaris Cuvier, 1797, caught by trawlers in Mallorca (Balearic Sea, western Mediterranean). Fish Res. 1998;36:237-49.

10. Sánchez P, Obarti R. The biology and fishery of Octopus vulgaris caught with clay pots on the Spanish Mediterranean coast.

11. Silva L, Sobrino I, Ramos F. Reproductive biology of the common octopus, Octopus vulgaris Cuvier, 1797 (Cephalopoda: Octopodidae) in the Gulf of Cádiz (SW Spain). Bull Mar Sci. 2002;71 (2):837-50.

12. López-Jurado JL, Balbín R, Amengual B, et al. The RADMED monitoring program: towards an ecosystem approach. Ocean Science Discussion. 2015;12:645-71.

13. Vargas-Yáñez M, Moya F, García-Martínez MC, et al. Relationships between Octopus vulgaris landings and environmental factors in the northern Alboran Sea (southwestern Mediterranean). Fish Res. 2009;99:159-67.

\section{*Correspondence to:}

Garcia-Martinez, MDC

Instituto Español de Oceanografía

Puerto Pesquero de Fuengirola s/n

29640 Fuengirola, Málaga

Spain

Tel: +0034 952197124

E-mail: mcarmen.garcia@ieo.es 